\title{
Multi-objective optimization identifies trade-offs between self-sufficiency and environmental impacts of regional agriculture in Baden-Württemberg, Germany
}

\author{
Christian Buschbeck, ${ }^{a *}$ Larissa Bitterich, ${ }^{\mathrm{b}}$ Christian Hauenstein, ${ }^{\mathrm{b}}$ and Stefan Pauliuk b, \# \\ University of Freiburg
}

Submitted July 18, 2019 / Revised February 28 and July 1, 2020 / Accepted July 1, 2020 /

Published online October 16, 2020

Citation: Buschbeck, C., Bitterich, L., Hauenstein, C., \& Pauliuk, S. (2020). Multi-objective optimization identifies trade-offs between self-sufficiency and environmental impacts of regional agriculture in BadenWürttemberg, Germany. Journal of Agriculture, Food Systems, and Community Development, 10(1), 43-62. https://doi.org/10.5304/jafscd.2020.101.003

Copyright (C) 2020 by the Authors. Published by the Lyson Center for Civic Agriculture and Food Systems. Open access under CC-BY license.

\begin{abstract}
Regional food supply, organic farming, and changing food consumption are three major strategies to reduce the environmental impacts of the agricultural sector. In the German Federal State of BadenWürttemberg (population: 11 million), multiple policy and economic incentives drive the uptake of these three strategies, but quantitative assessments of their overall impact abatement potential are lacking. Here, the question of how much food can be produced regionally while keeping environmental impacts within political targets is tackled by

\footnotetext{
a $*$ Corresponding author: Christian Buschbeck, Industrial Ecology Group, Faculty of Environment and Natural Resources, University of Freiburg; Tennenbacher Strasse 4; D-79106 Freiburg, Germany; christian.buschbeck@,indecol.unifreiburg.de

b Industrial Ecology Group, Faculty of Environment and Natural Resources, University of Freiburg

\# Author handling the submission and review process: Stefan Pauliuk; stefan.pauliuk@indecol.uni-freiburg.de
}

comparing a scenario of maximum productivity to an optimal solution obtained with a multi-objective optimization (MO) approach. The investigation covers almost the entirety of productive land in the state, two production practices (organic or conventional), four environmental impact categories, and three demand scenarios (base, vegetarian, and vegan). We present an area-based indicator to quantify the self-sufficiency of regional food supply, as well as the database required for its calculation. Environmental impacts are determined using life cycle assessment. Governmental goals for reducing environmental impacts from agriculture are used by the MO to determine and later rate the different Pareto-efficient solutions, resulting in an optimal solution for regional food supply under environmental constraints. In the scenario of maximal output, self-sufficiency of food supply ranged between $61 \%$ and $66 \%$ (depending on the diet), and most political targets could not be met. On the other hand, the optimal solution showed a higher share of organic production (ca. $40 \%-80 \%$ com- 
pared to $0 \%$ ) and lower self-sufficiency values (between $40 \%$ and $50 \%$ ) but performs substantially better in meeting political targets for environmental impact reduction. At the county level, selfsufficiency varies between $2 \%$ for densely populated urban districts and $80 \%$ for rural counties. These results help policy-makers benchmark and refine their goalsetting regarding regional selfsufficiency and environmental impact reduction, thus ensuring effective policymaking for sustainable community development.

\section{Keywords}

Environmental Impact, Evolutionary Algorithm, Foodshed, Life Cycle Assessment, Multi-Objective Optimization, Organic Farming, Regional Agriculture, Self-Sufficiency, Scenario Analysis, Germany

\section{Introduction and Literature Review}

\section{Problem Setting}

Agriculture and animal husbandry contribute significantly to the two most pressing environmental problems globally: climate change and nitrogen pollution (Smith et al., 2014; UNEP, 2013). At the same time, they form the largest employment sector in developing economies and still employ 27 million people in the Organization for Economic Co-operation and Development (OECD) countries (OECD, 2019). Agriculture and animal husbandry are directly linked to and affected by the Sustainable Development Goals and related targets (United Nations General Assembly, 2015), including the goals 'Zero Hunger,' 'Responsible Consumption and Production,' and 'Life on Land.' Transforming food production systems is, therefore, a major leverage point for sustainable development, both from the environmental and the health and social perspectives (Foley et al., 2011; Schmidt-Traub, Obersteiner, \& Mosnier, 2019; Tilman \& Clark, 2014).

\section{Regional and Organic Agriculture}

In developed economies, regional and organic agriculture are two widely discussed and promoted supply-side solutions for sustainable food provision. Further, consumers are often willing to pay higher prices for these products compared to conventional and non-regional products (Brunori et al., 2016; Theurl, 2016).

Organic agriculture, defined as an integrated farming system that strives for sustainability, the enhancement of soil fertility, and biological diversity, is an ongoing sustainability transformation in the sector that can cause less environmental damage and greenhouse gas (GHG) emissions per hectare than conventional agriculture (Badgley et al., 2007; Erb et al., 2009; Muller et al., 2017; Reganold \& Wachter, 2016). Meta-studies on the topic outline that organic farming leads to significantly higher soil organic matter content and soil nitrogen, an increase in biodiversity, and a decrease in energy turnover (Mondelaers, Aertsens, \& van Huylenbroek, 2009; Tuomisto, Hodge, Riordan, \& Macdonald, 2012). Yet these benefits generally come with lower yields (Seufert, Ramankutty, \& Foley, 2012), which leads to higher land use compared to conventional food production. Due to the often lower yields in organic production, organic agriculture's per product impacts can be higher than those from conventional agriculture (Seufert \& Ramankutty, 2017), and its potential to create and ensure food security worldwide is limited (Connor, 2008; Seufert et al., 2012).

The spatial extent of food supply chains is another debated issue in sustainable food production (Born \& Purcell, 2006; Brunori et al., 2016; Edwards-Jones, 2010; Edwards-Jones et al., 2008). Recently, there has been an increasing demand for regionally produced food in Germany (Feldmann \& Hamm, 2015) because many consumers expect social and environmental benefits from its consumption (Zepeda \& Deal, 2009). However, the actual environmental impacts of regional agriculture are highly debated. For example, Schlich and Fleissner (2005) showed that, regarding energy turnover, traveling distance is of minor concern compared to production practices, at least for some products. They argue that due to efficiency of scale, large businesses produce more efficiently than smaller ones. Contrarily, Andersson and Ohlsson (1999) came to the conclusion that besides a lower energy turnover, smaller bread production systems have less impact on eutrophication, acidification, and ozone-depleting substance 
formation compared to a larger, industrial one. Similarly ambiguous are the results of several studies that compared the footprint of apples consumed in Europe, originating from Europe and New Zealand respectively (Jones, 2002; Milà i Canals, Cowell, Sim, \& Basson, 2007; Saunders, Barber, \& Taylor, 2006; Stadig, 2001). EdwardsJones et al. (2008) highlighted the importance of system boundary definitions and advocated for the inclusion of social and economic factors when evaluating whether local food is the better option or not. Currently, the share of organic products consumed in Germany is rising (Statista, 2013), and regional products are politically supported (e.g., in the German federal state of Baden-Wuerttemberg; MLR, 2017).

\section{Trade-offs in Agriculture and Multi-objective Considerations}

Maximizing the output of an agricultural production system is optimal in terms of demand fulfillment but not in terms of environmental pressures. Trade-offs between different sustainable development goals also exist for regional food production. A widely used technique to analyze such trade-offs in agriculture is multi-objective optimization (MO) (Holzkämper, Klein, Seppelt, \& Fuhrer, 2015). For example, Lautenbach, Volk, Strauch, Whittaker, and Seppelt (2013) used MO to assess the trade-off between biofuel and food production in terms of their respective yields, water discharge, and nitrate leaching. They concluded that the methodology can be a helpful tool in the management of ecosystem services. A study conducted by Galán-Martín, Vaskan, Antón, Esteller, and Guillén-Gosálbez (2017) used results of life cycle assessments to optimally allocate agricultural land to either rain-fed or irrigated wheat production in Spain.

Trade-offs also apply to regional production of organic food: It may be possible to decrease environmental impacts by scaling up organic agriculture, but this is likely to decrease the amount of food that can be produced within a region due to lower yields (Zasada et al., 2019). While trade-off relationships between environmental impacts and productivity of organic farming are addressed frequently in the literature (Azadi, Schoonbeek, Mahmoudi, Derudder, De Maeyer, \& Witlox, 2011;
Seufert et al., 2012; Tuomisto et al., 2012), their connection to regional self-sufficiency of agricultural products (lower productivity means lower self-sufficiency rates) has not been studied in detail.

\section{Research Gap, Goal, and Scope}

In particular, the question of how regional food supply potential changes if different environmental impacts are included in the optimization process is understudied. A prerequisite for such an analysis would be an indicator for a region's potential selfsufficiency (e.g., what is possible with given sociogeographic conditions?). Although many indicators exist that represent the status-quo regarding a region's self-sufficiency (Blay-Palmer, Santini, Dubbeling, Renting, Taguchi, \& Giordano, 2018; Pradhan, Lüdeke, Reusser, \& Kropp, 2014; Strolling of the heifers, 2019), none of them is suitable to calculate potential self-sufficiency rates under different scenarios. This is because they use actual production, or monetary data instead of estimating production based on the agricultural land and its use. A research tool that determines how self-sufficiency changes under different demand scenarios and environmental impact reduction targets could not be found in the literature either.

The German Federal State of BadenWurttemberg (BW) has strong lobby group and political support for organic regional agriculture, e.g., in the form of so-called "bio-pioneer regions," which are promoted using the slogan, "Bio + Regional = Optimal” (Ministerium für Ländlichen Raum \& Verbraucherschutz Baden-Württemberg, 2019). But to what degree self-sufficiency of regional food supply is even possible in BW is not known. Also unanswered is the question of whether BW's agricultural production system could meet political emission targets under maximal output. We want to fill the aforementioned research gap for BW by addressing the following research questions:

1. How large is the maximal possible self-sufficiency of food supply for BW?

2. How compatible is a scenario of maximum self-sufficiency with political environment protection goals?

3. What would be an optimal solution that 
ensures relatively high self-sufficiency with relatively low environmental impacts?

4. How do the answers to questions $1-3$ change under different demand patterns and production practices?

Condensed into one goal that answers all of these questions, it means that we want to:

Analyze the trade-off relationship between self-sufficiency and environmental impacts by comparing a state of maximum selfsufficiency with the optimum of these opposing objectives for different demand and production patterns

To tackle this goal, we compiled a comprehensive database of agricultural plots and pastures within the state, sorted by possible crop sequences, as well as life cycle inventories of crop production. We defined a set of food demand scenarios, derived a suitable definition of the 'regional self-sufficiency rate' for food demand across all categories, and applied a multi-objective optimization. In the supplementary material, we also provided results to the question, "How big is the self-sufficiency regarding regional food supply of different subregions of Baden-Württemberg across all demand categories?"

The study focuses on the state of BW because there is strong political support for regional agriculture and community development on the governmental, county, and city levels (Ministerium für Ländlichen Raum \& Verbraucherschutz BadenWürttemberg, 2019). In order to inform the political and community development process at the state level, the geographical scope is limited to the state boundaries. Optimizing a food system with regional scope will of course lead to a very different outcome compared to a scope including national or global markets. It is not our research goal to provide optimal outcomes with supraregional scope, as that would require significantly more data and explicit modeling of global markets for agricultural commodities. Instead, our intention is to quantify the environmentally optimal outcome for a set of scenarios conceived under the premise that a high share of regional supply is a paramount objective. In such a situation and given that imports to $\mathrm{BW}$ are very small compared to the overall market volume for different commodities, we can assume that sufficient import quantities will be available irrespective of the optimization outcome for BW. Hence, the production and impacts of imported commodities do not need to enter the BW-focused optimization.

\section{Applied Research Methods}

We applied a multi-objective optimization to obtain a first estimation of the possible regional self-reliance of food production (Peters, Wilkins, Rosas, Pepe, Picardy, \& Fick, 2016).

\section{Multi-objective Optimization with Evolutionary Algorithms}

Multi-objective optimization algorithms are applied to problems with several opposing objectives. They try to minimize (or maximize) all objectives at the same time. With the number of objectives, the dimension of the decision space increases (Deb, 2014). Thus, for optimizations with more than one objective, the result is not one specific point but rather a set of points that are all equally (Pareto-) optimal (Konak, Coit, \& Smith, 2006). A point within the solution space is called Pareto-optimal if it is not possible to better one objective without worsening another (Ehrgott, 2012). The set of Pareto-optimal points, which is determined by multi-objective optimization, is called Pareto front or Pareto set. It can be examined with a variety of visualization methods to gain insight into trade-off relationships and possible best solutions (Tusar \& Filipic, 2015). Yet, finding one best solution is nontrivial because, at some point, the different objectives need to be compared and weighed against one another. The procedure developed by Blasco, Herrero, Sanchis, and Martínez (2008), which is also used in this study, solves this issue by defining desirability classes for each objective and applying a scoring system that follows the 'one vs. others criteria' (cf. supplementary material) introduced by Messac (1996). Where possible, desirability classes for the different environmental objectives were defined according to actual emissions and existing governmental goals.

In the field of multi-objective optimization, the 
family of evolutionary algorithms (EA) is widely used to determine the Pareto set (Deb, 2014). EAs are stochastic search algorithms that try to optimize a target function by mimicking evolutionary processes like mutation, crossover, and selection (Baeck \& Schwefel, 1993). The target function is chosen in accordance with the research goal. Here, we determine an optimal outcome by maximizing self-sufficiency and minimizing environmental impacts by altering how the available land is cultivated in terms of which field crop is produced on which land class, and which production practice is used. The objective function is a vector $\mathrm{Q}$, whose

\section{Figure 1. Workflow of the Multi-objective Optimization}

$\mathrm{Q}$ is the vector of the produced amount of food for every product. "Per-cap. demand" is the per-capita demand; LCA: life cycle assessment; LSS: level of regional self-sufficiency of food supply; MO: multi-objective optimization; EA: evolutionary algorithms.

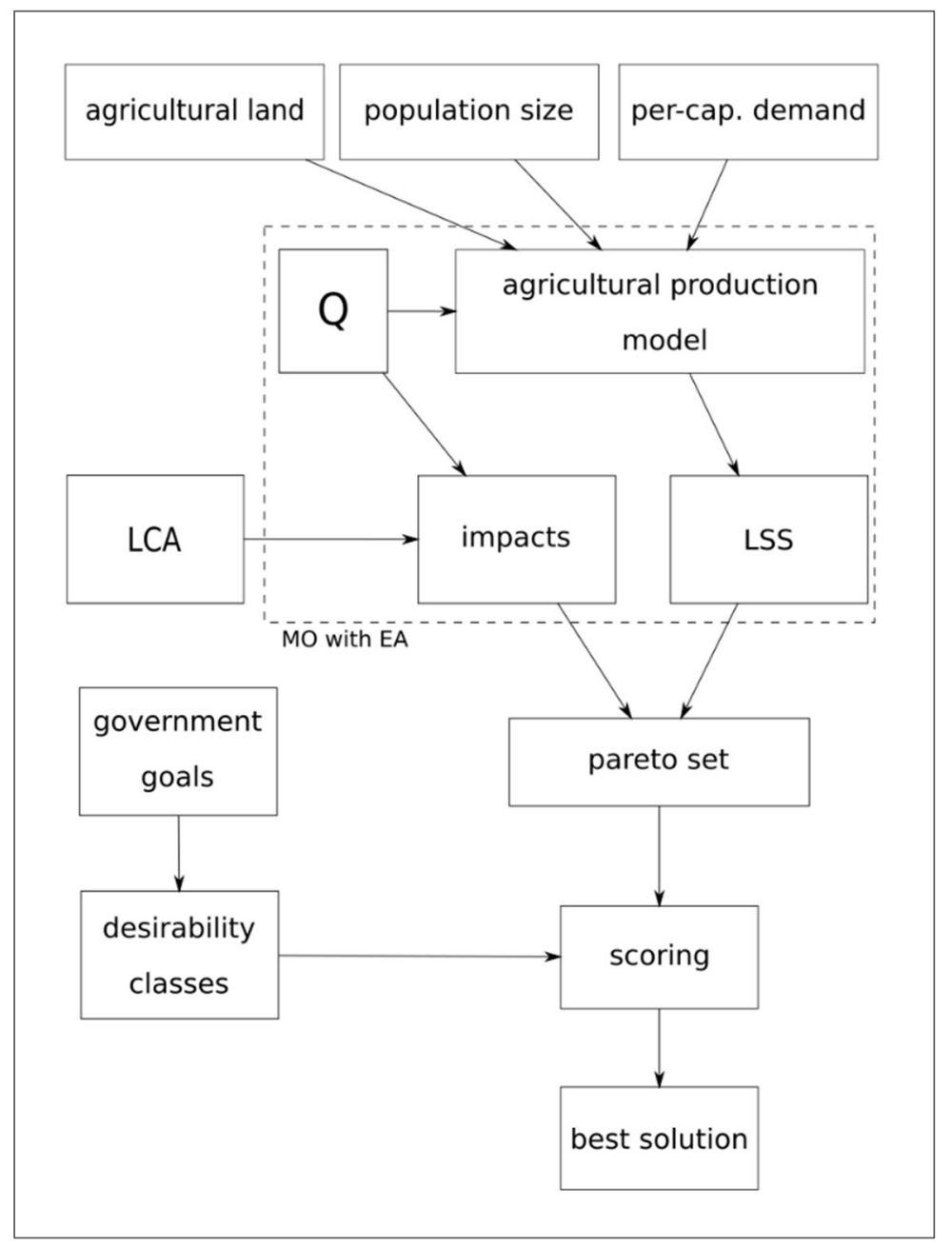

elements denote the mass of the different agricultural products supplied by the land within the region's boundaries. To incorporate production practice, each product is represented by two elements-one for organic and one for conventional production. According to the research goal, the objectives that should be optimized by altering $Q$ are:

a. A quantitative measure of self-sufficiency

b. Environmental impacts induced by regional agriculture.

As a measure of self-sufficiency, we introduce an area-based indicator called 'level of self-sufficiency' (LSS). For its calculation we developed an agricultural production model and compiled the required database of land plots and production life cycle inventories (LCI). Environmental impacts are calculated by scaling up the life cycle inventories (LCI) of the individual products and production practices following the life cycle assessment (LCA) methodology (Figure 1). Research question 4 is investigated by repeating the procedure with alternative food demand scenarios, and the question on county-level results is answered by reducing the geographical scope from the state to the county level.

\section{Level of Self-Sufficiency}

Self-sufficiency is a key indicator in characterizing regional agriculture. It describes to what extent the final food demand within a foodshed can be met with products that are produced within it. Here, instead of referring to Hedden (1929), who first introduced the term foodshed, we rely on a more recent definition from Peters, Bills, Lembo, Wilkins, and Fick (2009), who describe it as "the land that could provide some portion of a population center's food needs within the bounds of a relatively circumscribed geographic area" (p. 73). Since self-sufficiency is an area-related problem, its indicator needs to be area- 
based as well. In contrast, weight- or calorie-based LSS values are misleading because they are not good proxies for food quality or environmental impacts, especially in cases where products vary significantly in their agricultural land occupation values (ALO) (examples are provided in the supplementary material). Thus, we propose the following area-based level of self-sufficiency indicator:

The LSS of any given foodshed is the area used for producing regionally consumed food, divided by a hypothetical area necessary to produce the amount of food that meets the inhabitants' total demand. The latter is calculated by assuming production practices and area yields are the same as for the regionally produced food ('mirrored agriculture' assumption). In other words, the available agricultural land and its use are extrapolated so that they meet the total demand.
To calculate LSS, information is needed about the amount of food consumed by the inhabitants, the amount of food produced in the foodshed, and how much agricultural land is occupied. In this study, demand data are compiled from official statistics, and the amount of produced food and the occupied area are estimated with an agricultural production model, which uses detailed information of the available agricultural land in BW.

\section{Demand}

Food consumption data representing typical German consumption is provided by the Ministry for Nutrition and Agriculture (Ministerium für Ernährung \& Landwirtschaft). It was converted to per capita values and aggregated into a representative market basket (Clancy et al., 2017) with 17 products in 14 main food product categories (Table 1).

During the aggregation process, food items that cannot be grown in BW (rice, cacao, fish, citrus fruits) or are of minor relevance in terms of cal-

Table 1. Per Capita Annual Demand for Agricultural Products and Product Categories*

\begin{tabular}{|c|c|c|c|c|}
\hline Agricultural product & Category & Base $[\mathrm{kg} / \mathrm{yr}]$ & Vegetarian [kg/yr] & Vegan $[\mathrm{kg} / \mathrm{yr}]$ \\
\hline carrots & carrots & 64.9 & 68.8 & 68.8 \\
\hline lettuce & lettuce & 35 & 37.1 & 37.1 \\
\hline sunflower & \multirow{2}{*}{ vegetable oil } & \multirow{2}{*}{80.5} & \multirow{2}{*}{147.1} & \multirow{2}{*}{184.8} \\
\hline rapeseed & & & & \\
\hline potatoes & potatoes & 178.2 & 238.7 & 238.7 \\
\hline rye & rye & 13 & 13.8 & 13.8 \\
\hline soybeans & soybeans & 1.3 & 45.3 & 73.4 \\
\hline sugarbeet & sugarbeet & 258.3 & 118.3 & 118.3 \\
\hline tomatoes & tomatoes & 38.7 & 41 & 41 \\
\hline wheat & wheat & 104.9 & 111.4 & 111.4 \\
\hline beef & beef & 9.4 & 0 & 0 \\
\hline eggs & eggs & 14.4 & 12.8 & 0 \\
\hline milk pasture fed & \multirow{2}{*}{ milk } & \multirow{2}{*}{401.9} & \multirow{2}{*}{414} & \multirow{2}{*}{0} \\
\hline milk arable fed & & & & \\
\hline pork & pork & 39.1 & 0 & 0 \\
\hline broiler & \multirow{2}{*}{ poultry } & \multirow{2}{*}{15.7} & \multirow{2}{*}{0} & \multirow{2}{*}{0} \\
\hline turkey & & & & \\
\hline
\end{tabular}

*The list excludes fruits, wine, cacao, tea, coffee, and the like. The multitude of available food products was converted and aggregated to categories of agricultural products (e.g., bread to wheat, second column). For some categories, different agricultural production inventories exist (first column). 
orie intake and food security in Germany; honey, nuts, game, rabbit, sheep, and horse were excluded. Fruit trees and vineyard cultivation were not included either because areas dedicated to their production are difficult to transform, and we reduced the dedicated agricultural land accordingly. For the different food categories, we designated certain products as representative for the entire category (e.g., soy as proxy for legumes). The aggregated market basket represents the base demand scenario for the study. It covers the demand reported by the Ministry for Nutrition and Agriculture to an extent of $80 \%$ for vegetable products, $90 \%$ for meat products and $100 \%$ for milk products (weight percentages). The base demand was altered according to Meier and Christen (2013) to estimate vegetarian and vegan demand scenarios respectively, which serve as reference cases for the optimization. The total demand is calculated by multiplying the per capita demand by the population of BW (Statistische Ämter des Bundes \& der Länder, 2018). For details see the supplementary information.

\section{Agricultural Land}

In order to obtain detailed and realistic information of the production potential within BW, high resolution geo-referenced terrain, climate, and soil data were combined with the requirements of the different agricultural food crops. We used this information to identify the unique combination of crops that can potentially be grown on all arable land plots. The result is a novel georeferenced vector database with 319516 individual agricultural plots at a resolution of ca. $60 \times 60 \mathrm{~m}$ for the German state of Baden-Württemberg, each tagged with data on soil quality (soil depth, stone content, and groundwater table, which determine plot-specific crop restrictions and crop sequence), and inclination (plots with an inclination of $>25 \%$ were excluded). This information is the central database of this work, and its compilation is described in detail in the supplementary material. For the land allocation procedure, the plots were aggregated into 137 different classes of arable land, by grouping plots with similar or identical crop sequence potentials. The total area of the different classes within $\mathrm{BW}$ ranges from 0.04 to ca. 330000 ha, with the five biggest land classes making up $78 \%$ of the total arable land (808615 ha) (Bundesamt für Kartographie und Geodäsie [BKG], n.d.; Kaule et al., 2011; VELA, 2014). Each of these land classes has specific yields and possible crop sequences for the 16 crops that serve as food or fodder crop (Table 2). Next to arable land, pasture is included as well, and the amount of pasture was retrieved from georeferenced land use data for BW (Bundesamt für Kartographie und Geodäsie, 2018). The details of compilation of the land class database are described in the supplementary material.

\section{Agricultural Production Model and LSS Calculation}

An agricultural production model was developed to calculate the levels of self-sufficiency for a given vector $\mathrm{Q}$ that lists the quantities for each product produced within the foodshed. In the model, all entries of Q are converted into the area needed to produce the respective food or fodder crops (e.g., 1 $\mathrm{kg}$ milk is expressed in terms of the area needed to produce the fodder required for its production). The area needed for a single crop is calculated by multiplying its quantity with its ALO-value. Crop rotation constraints are taken into account with crop rotation factors, which indicate the proportion of the area within a land class that is maximally available for a single crop. For example, if one crop

Table 2: Which Crops (Food and Fodder) Can Be Grown in the Five Biggest Land Classes

\begin{tabular}{|c|c|c|c|c|c|c|c|c|c|c|c|c|c|c|c|c|}
\hline Class & Area (ha) & Carrots & Salad & Potato & $\begin{array}{l}\text { Rape- } \\
\text { seed }\end{array}$ & Rye & Pea & $\begin{array}{c}\text { Sugar- } \\
\text { beet }\end{array}$ & $\begin{array}{l}\text { Sun- } \\
\text { flower }\end{array}$ & $\begin{array}{c}\text { Toma- } \\
\text { toes }\end{array}$ & Wheat & Barley & $\begin{array}{l}\text { Maize } \\
\text { (corn) }\end{array}$ & $\begin{array}{l}\text { Maize } \\
\text { (silage) }\end{array}$ & Soy & Triticale \\
\hline 1 & 334,557 & $\checkmark$ & $\checkmark$ & $\checkmark$ & $\checkmark$ & $\checkmark$ & $\checkmark$ & $\checkmark$ & $\checkmark$ & $\checkmark$ & $\checkmark$ & $\checkmark$ & $\checkmark$ & $\checkmark$ & $x$ & $\checkmark$ \\
\hline 2 & 177,726 & $\checkmark$ & $\checkmark$ & $\checkmark$ & $\checkmark$ & $\checkmark$ & $\checkmark$ & $\checkmark$ & $\checkmark$ & $\checkmark$ & $\checkmark$ & $\checkmark$ & $\checkmark$ & $\checkmark$ & $\checkmark$ & $\checkmark$ \\
\hline 3 & 59,562 & $\checkmark$ & $\checkmark$ & $\checkmark$ & $\checkmark$ & $\checkmark$ & $\checkmark$ & $\checkmark$ & $x$ & $\checkmark$ & $\checkmark$ & $\checkmark$ & $\checkmark$ & $\checkmark$ & $x$ & $\checkmark$ \\
\hline 4 & 37,799 & $x$ & $\checkmark$ & $\checkmark$ & $\checkmark$ & $\checkmark$ & $\checkmark$ & $\checkmark$ & $\checkmark$ & $\checkmark$ & $\checkmark$ & $\checkmark$ & $\checkmark$ & $\checkmark$ & $x$ & $\checkmark$ \\
\hline 5 & 20,980 & $x$ & $\checkmark$ & $x$ & $x$ & $\checkmark$ & $\checkmark$ & $x$ & $x$ & $\checkmark$ & $\checkmark$ & $x$ & $\checkmark$ & $\checkmark$ & $x$ & $\checkmark$ \\
\hline
\end{tabular}


can only be farmed every third year, the model would allocate a maximum of $33 \%$ of that land class to that crop. The crop rotation factors were taken from KTBL (2009) and Rippel (2014). For a given crop, ALO-values and crop rotation factors may be different for organic and conventional production. The model consecutively allocates the area needs of the different crops to the land classes where they can be grown, and diminishes the remaining available area within those land classes accordingly.

In the allocation process, both land classes and crops are used in a certain order, which is based on how flexibly they can be used to farm different crops: By using up "picky" land classes and restricted crops first, it is assured that the area is used efficiently. After all crops are allocated to corresponding land classes, the area needed for each product category $c\left(n_{c}[\mathrm{ha}]\right)$ is calculated. With Q (population size times per-capita demand) the model also calculates product category specific demand fulfillment rates $\left(r_{c}[\%]\right)$. These values indicate to what extent the demand of a given category is met, and they are used to estimate the area that would be needed if the total demand would be met. In the calculation of demand fulfillment rates, coupled products are treated in a system expansion approach: The production of one kiloton of a main product (eggs, milk), automatically produces a certain amount of poultry and beef respectively (as coproducts). With given $n_{c}$ and $r_{c}$ the area-based LSSvalues can be calculated:

$$
\operatorname{LSS}(Q)=\frac{\sum_{c=1}^{14} n_{c}(Q)}{\sum_{c=1}^{14} n_{c}(Q)+\sum_{c=1}^{14}\left(n_{c}(Q) * \frac{100-r_{c}(Q)}{r_{c}(Q)}\right)}(1)
$$

The numerator represents the area that is needed for producing Q. The denominator represents the area that is needed if the local demand would be met. It is the sum of what is needed to produce $\mathrm{Q}$ and what is needed to produce the 'missing part' of the demand. For example, assume a category's demand fulfillment rate is $75 \%$ and it needs 30 ha arable land. Then (100-75)/75 multiplied with 30 ha yields 10 ha as the area needed to cultivate the missing $25 \%$.

This hypothetical area of 10 ha automatically possesses the same composition of products and production practices as the actually produced food because it was calculated from its demand fulfillment rate (mirrored agriculture). Note, here, that the hypothetical area is only used as an extrapolation of the available agricultural land (and its use) in order to quantify LSS and does not relate to any actual production.

In case the available agricultural land is exceeded, or overproduction occurs for any category $\left(r_{c}>100\right)$, LSS is set to zero as penalty for the optimization (overproduction of one category will leave less area for the others). For poultry and beef, the demand fulfillment rates are adjusted to include cases where they are co-products of egg and milk production.

\section{Environmental Impact Calculation with LCA}

Total potential environmental impacts induced by agriculture were calculated by scaling up product specific LCIs calculated for one kiloton of raw product at the farmgate as reference flow. The assessment contained all upstream products including, e.g., energy and fertilizer use. The LCAs were performed in openL CA v. 1.6 with the AGRIBALYSE v. 1.3 database. This was chosen after extensive review of the existing LCI databases because it allows for detailed comparison of conventionally and organically grown products (cf. supplement). The farming processes selected from AGRIBALYSE v1.3, which reflect French agricultural practice in a climate similar to that of BW, were adapted to reflect regional production in BW by changing the electricity mix. With these modified process inventories, midpoint indicators according to the ReCiPe 2008 life cycle impact assessment method (Goedkoop et al., 2009) were calculated for four salient agricultural impact categories (Stoate, Boatman, Borralho, Carvalho, Snoo, \& Eden, 2001): climate change (CC), marine eutrophication (ME), terrestrial acidification (TAC), and terrestrial ecotoxicity (TET). It is important to note that in the ReCiPe 2008 method, marine eutrophication refers to nitrogen eutrophication to the water body in contrast to freshwater eutrophication, which refers to phosphorus eutrophication.

For some products, the database only contains conventional production. In the case of beef and 
turkey production, LCIs of the organic counterpart were estimated by taking the conventional processes and changing the fodder input to an organic diet with the same energy content. In the case of organic milk production, only a single management system is available in the LCI database and is used in our model. It represents a feeding system relying on grazed grass as well as concentrate feed such as silage corn. For vegetable products where LCIs are not available (two conventional and six organic products), data from either the conventional counterpart or a similar crop was used as proxy. Because the impacts are later related to governmental goals concerning German emissions, only those emissions taking place within the country of production are included in the impact assessment step of the LCA. In the objective function of the MO, the amount of every product (i.e., each element of Q) is multiplied with the corresponding characterized life cycle inventory result of that product. By summing up the emissions of all products per impact category, the total emissions of $\mathrm{Q}$ are obtained (in other words the line vector Q is multiplied with the column vector of the respective LCI).

\section{Conducting the $M O$}

The MO was conducted with the widely used NSGAII algorithm (Deb, K., Pratap, A., Agarwal, S., \& Meyarivan, T. 2002), which is designed to minimize all objectives. Because LSS needs to be maximized, for the optimization it was transformed into negative LSS by multiplying it with minus one. The other objectives (environmental impacts) are calculated as described above, resulting in the following target function:

$$
\operatorname{fitness}(\vec{Q})=\vec{F}=\left(\begin{array}{c}
\vec{Q} * \overrightarrow{L C I_{C C}} \\
\vec{Q} * \overrightarrow{L C I_{M A}} \\
\vec{Q} * \overrightarrow{L C I_{T A C}} \\
\vec{Q} * \overrightarrow{L C I_{T E T}} \\
-L S S(\vec{Q})
\end{array}\right)
$$

It is a function of $\vec{Q}$ and the outcome is another $\operatorname{vector}(\vec{F})$ with five elements that are all subject to minimization (Note that $\vec{Q}$ is a column vector and the respective $\overrightarrow{L C I}$ vectors are row vectors).
In order to properly approximate the Pareto front, the algorithm needs boundaries and reasonable start values for $\mathrm{Q}$ (first-generation). These were obtained by a mechanistic approach that gradually increases the amount of each product simultaneously until the demand is met or the area is exceeded. A random element was chosen from the solution set generated by that approach to ensure that the first generation has a big enough variety. The parameter population size (not to be confused with the population of $\mathrm{BW}$ ) defines the number of individuals within one generation of the algorithm and by that, the number of points in the resulting Pareto set. To ensure that the Pareto set is large enough to broadly reflect the Pareto front, it was set to 1500 , reflecting typical choices in the literature. The MO was run with a probability for mutation of 0.2 and a probability for crossover of 0.7 over 5000 generations. Mutation randomly alters a number of elements within Q whereas crossover creates "offspring" by combining two Qs ("parents") according to a specified operator. In this study an operator that, element-wise, calculates the mean of the two "parents" was used.

\section{Desirability Classes}

The methodology from Blasco et al. (2008) for retrieving an $\mathrm{MO}$ solution needs pre-defined desirability classes for every objective. In this study the classes include the following: highly undesirable $(\mathrm{HU})$, undesirable $(\mathrm{U})$, tolerable $(\mathrm{T})$, desirable $(\mathrm{D})$, and highly desirable (HD). For climate change, eutrophication, and terrestrial acidification, desirability thresholds were defined according to actual emissions (undesirable) and governmental goals (highly desirable) developed by the institutions BMU (n.d.), MUKE BW (n.d.), and Umwelt Bundesamt (UBA) (2018) (for details, cf. Supplement). Because state level emission data and goal definitions for climate change and terrestrial acidification were not available for BW, corresponding data for Germany were scaled down using the share of BW in German agricultural output. For terrestrial ecotoxicity, no emission data was available, so its range within the Pareto set was divided into five equally sized intervals. We defined the thresholds for LSS according to what is maximally possible in $\mathrm{BW}$ if environmental constraints 
Table 3. Desirability Thresholds and Scores for the Desirability Classes*

\begin{tabular}{c|c|c|c|c|c|c}
\hline Objective** & Unit & HD & D & T & U & HU \\
\hline CC & kt CO2-eq & $<4737.1$ & $<5021.9$ & $<5306.6$ & $<5591.4$ & $\geq 5591.4$ \\
\hline ME & kt N-eq & $<10.4$ & $<17.3$ & $<24.26$ & $<31.2$ & $\geq 31.2$ \\
\hline TA & kt-SO2-eq & $<84.8$ & $<90.6$ & $<96.3$ & $<102$ & $\geq 102$ \\
\hline TET & kt 1,4 DCB-eq & $<90$ & $<175.7$ & $<261.4$ & $<347.1$ & $\geq 340.1$ \\
\hline LSS & $\%$ & $>60$ & $>50$ & $>40$ & $>30$ & $\leq 30$ \\
\hline & Score & 0 & 1 & 6 & 31 & 156 \\
\hline
\end{tabular}

* For the five objectives described above, the desirability classes are highly desirable (HD), desirable (D), tolerable (T), undesirable (UD), and highly undesirable (HU).

** The acronyms are climate change (CC), marine eutrophication (ME), terrestrial acidification (TAC), terrestrial ecotoxicity (TET), and level of self-sufficiency (LSS).

are not accounted for. Table 3 shows the desirability thresholds for the different objectives. A score was assigned to every desirability class (Table 3, bottom) according to the scheme described by Blasco et al. (2008), which fulfills the 'one vs others' criteria (i.e., bettering one objective in a given class is preferred over bettering all other objectives in the next best class) (Messac, 1996). By summing up the scores of every class, the total score of a point within the Pareto set is derived. The lower it is, the better the point performs regarding the desirability of the different objectives. The best point is then determined by choosing the point with the lowest score out of all possible points.

\section{Results}

The regional self-sufficiency of food supply was maximized while minimizing environmental impacts in order to analyze the trade-off relationship between the opposing objectives. Figures 2-4 show so-called level plots (Blasco et al., 2008) of the multi-objective optimization for base-, vegetarian-, and vegan-demand scenarios. Level plots show the whole Pareto set for one specific objective. The $\mathrm{x}$ axis represents the different objective values in physical units whereas the y-axis represents a norm that describes the distance to an ideal point. For this hypothetical point, the value of every objective is the minimal, and the point with the lowest norm value is closest to the ideal point. Here, the infinity norm was applied because it is best suited for visualizing trade-offs between conflicting objectives. Because the same norm is shown for each of the different objectives, one can compare the performance of a certain point regarding different objectives. Desirability classes and their thresholds are shown as colored background and dashed grey lines to show how desirable different points are for each objective. Additionally, a scoring system which is described in detail in the supplement, was applied to the points in the Pareto set. In the plot the score is shown as the points' coloring. The lower the score, the better a point performs concerning the defined desirability classes. The best solution (i.e., the point with the lowest norm value among those, with lowest score) is shown as a red triangle. The red rectangle represents the point of maximum LSS.

In the level plots, the trade-off between LSS and environmental impacts is visible: Outcomes with increasing impact values are less desirable (darker background) while increasing LSS values leads higher desirability (brighter background).

For every objective, moving towards either very small or very high values will eventually increase the distance to the ideal point (expressed as infinity norm) because performance regarding one of the opposing objectives is worsened too severely. The case of maximum LSS is one of those extremes. Here, LSS values range between 61 and $66 \%$ (research question no. 1), depending on the demand scenario (Table 4). For all diets, soy is a limiting factor in LSS maximization because its overall production potential in BW is low. In the base demand scenario, soy is primarily needed as animal fodder, in the vegan diet as vegetable food 


\section{Figure 2. Pareto Set with 1,500 Elements of a Multi-objective Optimization for Four Environmental Impacts and the Level of Self-sufficiency in the Form of Level Plots. The MO was conducted for a base food demand scenario.}

The set contains 1,500 points that represent the Pareto front. The Pareto-efficient solutions are plotted using the infinity norm as $y$-axis coordinate, and they are evaluated according to the desirability classes defined in table 3 and a score based on these classes. The red triangle represents the optimum obtained by this approach; the red square represents the state of maximum LSS.

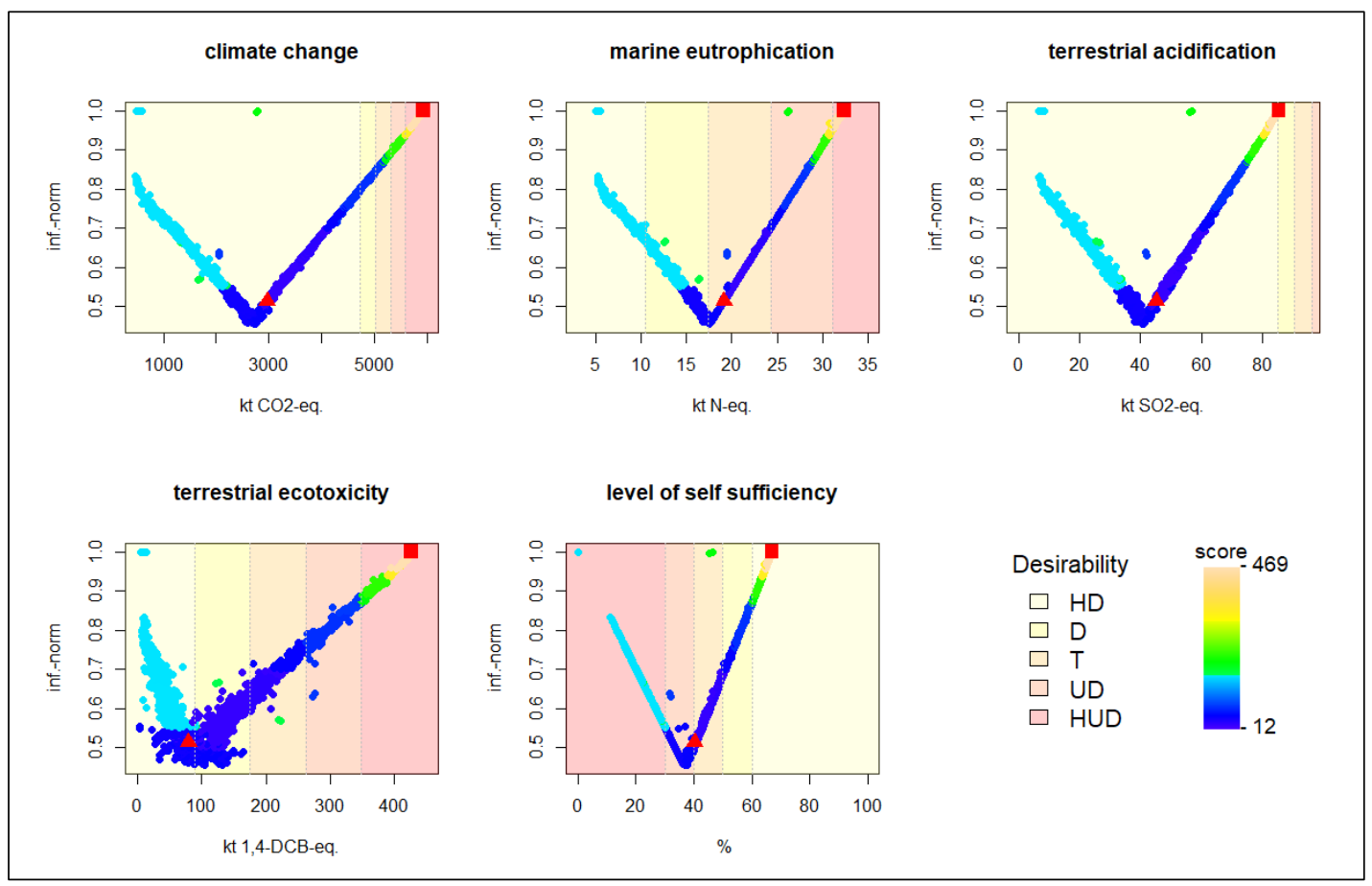

and in the vegetarian for both. Compared to the vegan demand scenario, the base and vegetarian demand scenarios have higher maximum LSS values, because, for the latter, pasture is available for food production (regulations and also partly political climate considerations prohibit the conversion of pastures to arable land).

The level plots show that the state of maximum LSS comes with strong environmental impacts: In the base and vegetarian demand scenario, the state of maximum LSS is in the highly undesirable section for climate change, marine eutrophication, and terrestrial ecotoxicity. In these impact categories political goals cannot be achieved in a state of maximum productivity (research question 2). For the vegan demand scenario only terrestrial ecotoxicity is in the undesired section for maximum LSS.

In contrast to maximized productivity, the $\mathrm{MO}$ optimum's values lay in moderate desirability clas- ses for all objectives (research question 3): For the base and vegetarian demand scenario, the optimum's worst section is 'tolerable,' for the vegan demand scenario its worst is the 'desirable' section. Among the different diets' optimums, the vegan demand scenario has the highest LSS value (50\%).

When the state of maximum LSS and the MO's optimum are compared (research goal), an overproportional decline in environmental impacts is visible (Figure 5). For example, in the base demand scenario, going from a point of maximum LSS to the optimum decreases self-sufficiency by $40 \%$ (27 percentage points), but also decreases climate change impacts and terrestrial acidification by half and terrestrial ecotoxicity by $80 \%$. Marine eutrophication decreases by about $40 \%$ as well. For the vegan demand scenario similar declines can be observed, but in the vegetarian demand scenario it is less distinct. For all demand scenarios, the production technology mix of the optimum comprises 
Figure 3. Pareto Set with 1,500 Elements of a Multi-objective Optimization (MO) for Four Environmental Impacts and the Level of Self-sufficiency in the Form of Level Plots. The MO was conducted for a vegetarian demand scenario.

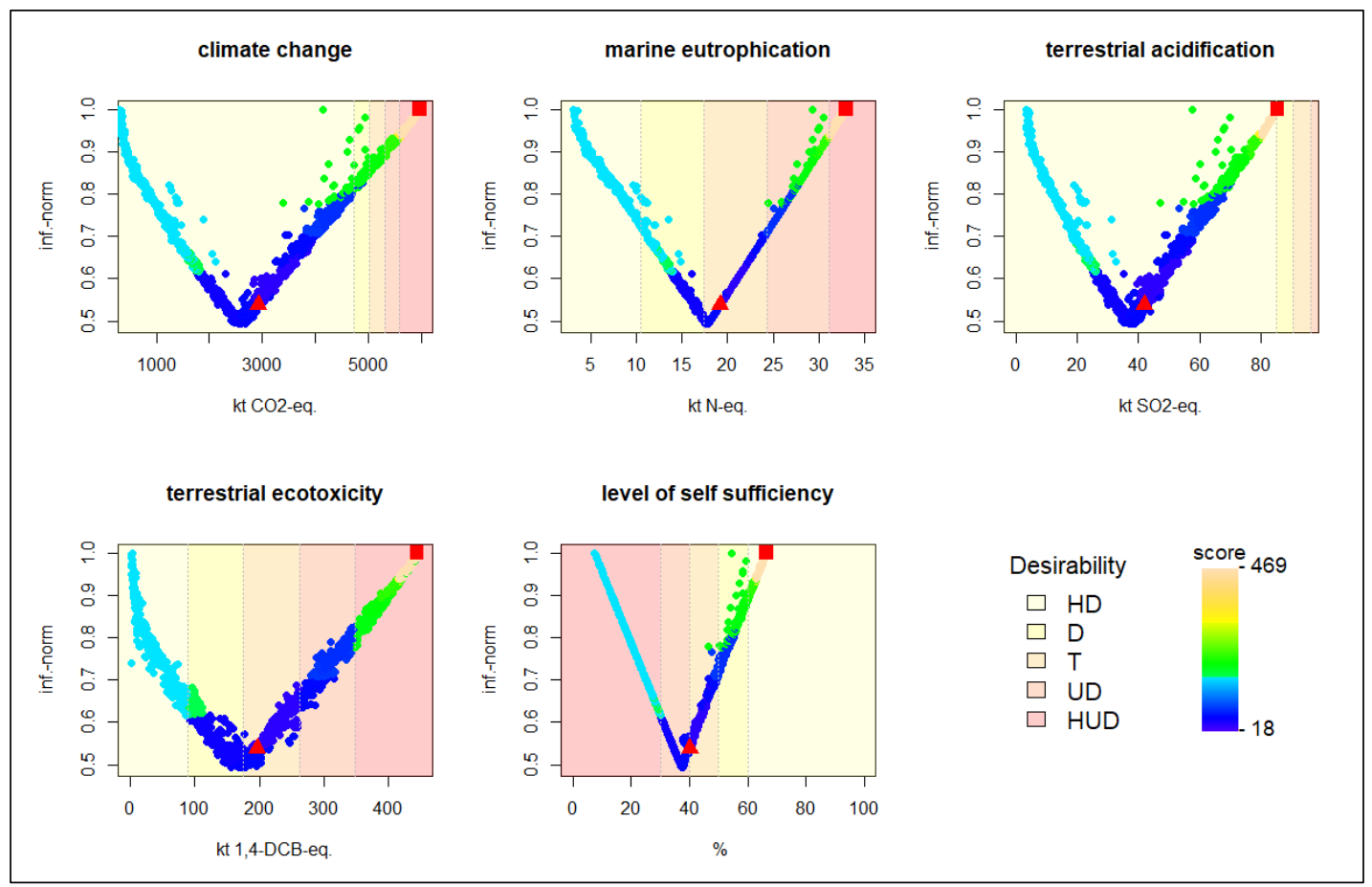

Figure 4. Pareto Set with 1,500 Elements of a Multi-objective Optimization (M0) for Four Environmental Impacts and the Level of Self-sufficiency in the Form of Level Plots. The MO was conducted for a vegan demand scenario.

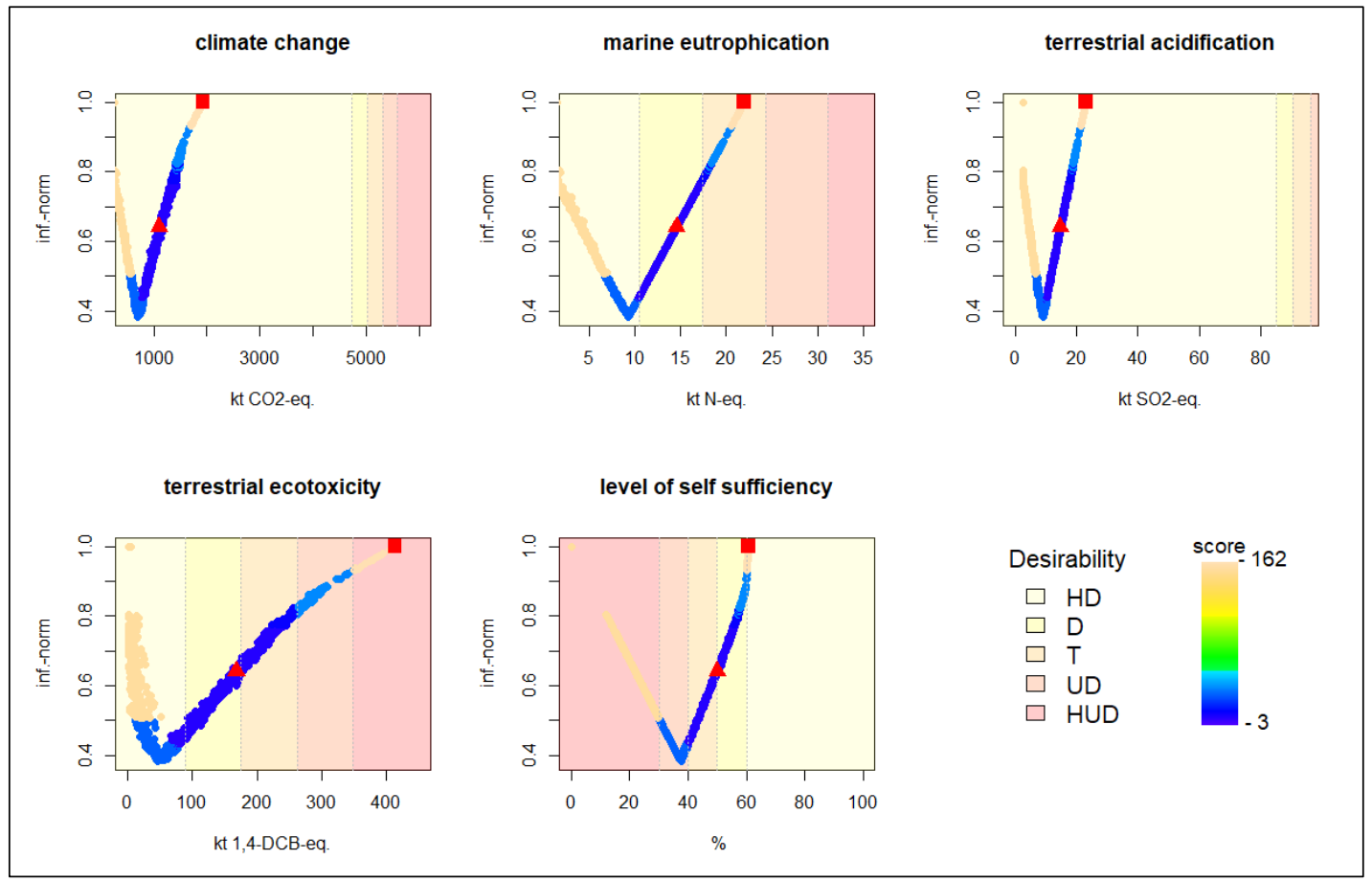


at least $40 \%$ organic agriculture (Table 4), which contributes to the nonlinear decline of environmental impacts (especially terrestrial ecotoxicity).

Interestingly, none of the Pareto-optimal points produced results where all the agricultural land is used. This indicates that in order to reach the proposed goals in environmental protection (which enter the routine via the desirability classes),

Table 4. Comparison of the Agricultural Land Allocation for a State Where Level of Self-sufficiency (LSS) is Maximized (Left) vs. the Best Solution of the Multi-Objective Optimization (MO, right)

\begin{tabular}{|c|c|c|c|c|c|c|c|}
\hline \multirow[b]{2}{*}{ Indicator } & \multirow[b]{2}{*}{ Unit } & \multicolumn{3}{|c|}{ Maximize LSS } & \multicolumn{3}{|c|}{ Optimum of MO } \\
\hline & & Base & Vegetarian & Vegan & Base & Vegetarian & Vegan \\
\hline Score* & 1 & 469 & 469 & 162 & 12 & 18 & 3 \\
\hline $\mathrm{CC}$ & kt & 5,929 & 5,981 & 1,926 & 2,966 & 2,923 & 1,095 \\
\hline $\mathrm{ME}$ & kt & 32 & 33 & 22 & 19 & 19 & 15 \\
\hline TAC & kt & 85 & 85 & 24 & 45 & 42 & 15 \\
\hline TET & kt & 426 & 444 & 413 & 79 & 197 & 168 \\
\hline LSS & $\%$ & 65 & 66 & 61 & 40 & 40 & 50 \\
\hline Arable land used & $\%$ & 93 & 95 & 80 & 74 & 77 & 76 \\
\hline Pasture used & $\%$ & 99 & 1 & 0 & 65 & 43 & 0 \\
\hline Share org. & $\%$ & 0 & 0 & 0 & 77 & 44 & 54 \\
\hline
\end{tabular}

* The score is the one obtained by the multi-objective optimization. CC stands for climate change, ME for marine eutrophication, TAC for terrestrial acidification, and TET for terrestrial ecotoxicity.

\section{Figure 5. Radarcharts of Performances Regarding Level of Sself-sufficiency (LSS) and Environmental Impacts in a State of Maximum LSS and the Multi-Objective's (MO's) Optimum}

Each chart is designated for a demand scenario and scaled according to the respective state of maximum LSS. Each objective's range is divided into five equal sections. Based on these sections, the overproportional decline of environmental impacts by going from a state of maximum LSS to the optimum is evident: for example, in the vegan demand scenario, the optimum's LSS value lies in the outmost section whereas all the impact values lie further within.

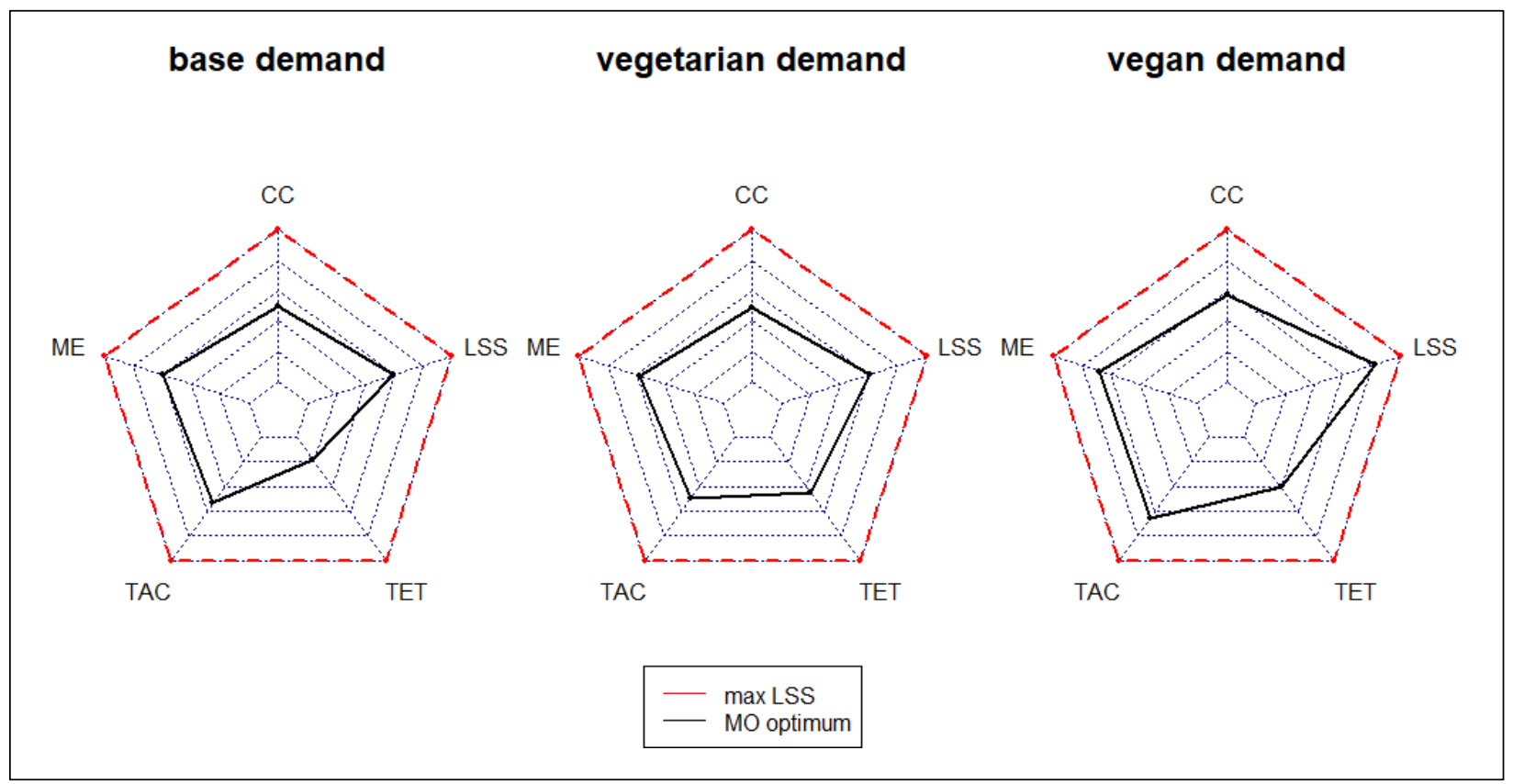


a shift toward more environmentally friendly production practices is not enough. There is also a need to produce less than what would be possible in the region by converting some land to fallow, which could lead to additional environmental benefits. The county specific LSS values, the resulting food quantities per product for all cases, and the demand fulfillment rates for each product category are listed in the supplementary material.

\section{Discussion}

The results show that a state of maximum selfsufficiency can reach LSS-values ranging from 61\% to $66 \%$ but fail to satisfy three out of four environment protection goals for base and vegetarian demand scenarios, and one out of four for the vegan demand scenario (research questions 1 and 2). The optimum retrieved by the MO is a compromise between opposing objectives and fulfills environmental requirements to at least a 'tolerable' degree, but only reaches LSS-values ranging from $40 \%$ to $50 \%$ (research question 3 ). With a vegetarian diet, it is possible to reach the highest level of self-sufficiency, because pasture, which cannot be converted to other land use types due to legal and partly climatic reasons, is utilized for dairy products. If environmental impacts are included in the optimization process, the vegan diet outperforms the other two not only in most impacts, but also in LSS (research question 4).

The decline in LSS-values under environmental constraints compared to a state of maximum LSS comes with an even greater decline in environmental impacts (research goal). For base and vegetarian demand, this overproportionality can partly be explained by a lower share of meat and/or milk products in the MO's optimum. Here, only $18 \%$ $21 \%$ (compared to $28 \%-29 \%$ in the LSS maximization) of the products are animal-based, whose production tends to put more pressure on the environment. Another central factor in impact reduction is the shift towards organic production (from $0 \%$ to around $40 \%-80 \%$ ) as the vegan demand scenario exemplifies.

\section{Policy Implications}

Optimization results such as the ones presented here show the extent to which conflicting objec- tives can still be achieved under best possible circumstances. This maximum potential impact of a sustainable development strategy provides a guardrail against which the different policy targets and the eventual real-world impacts can be benchmarked. It also shows the potential of a given strategy in relation to what other strategies can achieve. It can be communicated to policy makers to show the potential of regional agriculture under different environmental and sustainability objectives. The policy targets themselves often do not directly build on optimization outcomes and are the result of a consensus-building process that takes into account the perspectives and power of different stakeholders. The main application of the $\mathrm{MO}$ results is thus not to be used directly as policy targets, but to make sure that policy targets are feasible in principle. This situation is similar to how energy system models are used to depict optimal future outcomes of the energy transition (Pfenninger, Hawkes, \& Keirstead, 2014). The process of informing policy target setting is best applied at the state and county level due to the coarse level of resolution of the land-use conditions and, in particular, the average process inventories for farming the different crops. Local, farm-level conditions may deviate substantially from the average and require other, locally optimal decisions. The results are by no means to be interpreted such that all organizational units, including farms, should adhere to the solutions found. Instead they can be used to set regional targets based upon the different incentives that regions devise for reaching them.

\section{Community Development for Sustainable Agriculture} The study presents an analysis of both the current and extreme diet alternatives, such as a completely vegan diet. The extreme cases were studied to map the solution space and show what changes in environmental impacts and self-sufficiency are possible in principle to then inform policy and public debates. From the analysis itself, we can conclude neither that such extreme developments are desirable nor that they are feasible. Instead, and this is where the true value of the study lies in our view, we show that sustainable development in the food system requires both: major shifts in farming prac- 
tices and major shifts in consumption patterns. The sustainability transformation on both productionand consumption-side has to be co-designed using a variety of planning and community development tools including transdisciplinary research. Urbanresident-driven initiatives such as the 'save the bees' campaign (proBiene-Freies Institut für ökologische Bienenhaltung, 2019) focus on one part only (here: the supply side) and under-appreciate the importance of community development required for adopting more sustainable farming practices. They tend to also ignore the system-wide consequences of their vision, such as a shifting of impacts to other regions as a result of increasing regional organic farming output without changes on the demand side (Muller et al., 2017; Smith, Kirk, Jones, \& Williams, 2019).

\section{Limitations of the Study}

Due to their stochastic nature, EAs can only approximate the Pareto set. We found that the NSGAII algorithm requires a very large computational effort to maintain a pressure towards the Pareto front when there are more than three objectives to optimize (Coello Coello, Aguirre, \& Zitzler, 2005). For the five objectives considered here, we therefore chose a very large population size $(1,500)$ and many generations $(5,000)$. A leaner solution would be to incorporate an adjustment in the algorithm according to Köppen and Yoshida (2007), but that was not possible within the scope of this study.

The food basket used in this study only contains a certain selection of food products to reflect German consumption. Therefore, the results only apply to a part of the total demand. Due to the fact that vegetable products are underrepresented compared to meat and milk products, the vegan demand scenario is biased in the sense that LSS is overestimated. On the other side, the choice of soy as the sole legume is a bias that might underestimate LSS for the vegan and vegetarian demand scenario because the land in BW that is suitable to grow soy is limited.

The approach presented here needs detailed geo-referenced land-use and census data. It was possible to conduct such a study for Germany, where such data is relatively easily accessible, but this may not be possible in regions with poorer data availability.

In general, LCA results come with high epistemic uncertainty due to the proxy choice made (use of aggregated AGRIBALYSE datasets) and the assumptions and uncertainties contained therein. In addition, there is an aleatory uncertainty of the LCI data of the different agricultural processes due to changing local and seasonal conditions. Especially the poor representation of distinctive impacts for different management systems in organic milk production is a major shortcoming and may overestimate the environmental impacts for base and vegetarian demand. Still, using those LCI datasets was the only feasible way to obtain reasonable impact estimates for regional agriculture in BW, and more region- and site-specific agricultural process inventories are needed to provide more accurate scenarios in the future, including potential yield changes as a consequence of climate change (Griffin et al., 2018). Considerations of the economic and political feasibility of the self-sufficiency rates and underlying scenarios, as well as the question of how and where the missing food should be produced and imported from without intense environmental damages, are of paramount importance but were beyond the scope of this study.

\section{Further Research}

Next to overcoming the limitations stated above, more site-specific process inventories are needed to increase the relevance of the MO-based approach at the local scale (farm cooperative or farm-level). Moreover, not only production but also scenarios and business models for storage, logistics and transport, and marketing need to be included in the system boundary to fully describe regional potential and sustainable relations between food production and consumption. More highresolution information is needed regarding the usage of plant protection agents, as the currently available information is very scarce. The regionbased scenarios should be contrasted with those including a depiction of global market for agricultural commodities to study the displacement and indirect land-use effects of substantial changes towards organic agriculture in $\mathrm{BW}$, as demon- 
strated for other regions by Muller et al. (2017) and Smith et al. (2019).

\section{Conclusions}

The study showed that regional agriculture in Baden-Württemberg cannot be fully self-sufficient regardless of the diet (level of self-sufficiency (LSS) ranges between $61 \%$ and $66 \%$ ), because of the high population density (310 inhabitants $/ \mathrm{km}^{2}$ ). Moreover, an agricultural production system targeted at maximum output, cannot meet all political environmental protection goals. Using multi-objective optimization, it was possible to identify optimal trade-offs between regional selfsufficiency and environmental impacts. The optimum is not only a compromise between the conflicting objectives (all objectives are at least 'tolerable' for base and vegetarian and at least 'desirable' for vegan demand scenario), but also eco-efficient in a sense that when compared to a state of maximum LSS, environmental impacts are reduced overproportionally compared to the LSS reduction. This overproportional decline in impacts is partly due to a shift towards organic production. The efficient state has a share of organic production of around $40 \%-80 \%$ (depending on the diet) and balances self-sufficiency and environmental impacts (according to governmental goals), with LSS-values around $40 \%-50 \%$. A shift towards a vegan diet (also if incomplete) has strong co-benefits regarding environmental impacts and self-sufficiency. Thus, another conclusion is that food production problems need to be tackled not only from the production but also from the consumption side.

The results presented may help policy-makers as well as community-driven initiatives to benchmark their transformation target suggestions, as they present a quantitative basis to substantiate an ongoing debate.

\section{Acknowledgments}

The authors want to express their gratitude to Prof. Dr. Rainer Grießhammer, Michael Asse, Frank Gräter, Jens Lansche, Dr. Hansjörg Nußbaum, Hansjörg Schrade, Franz Schweizer, and Dr. Aurélie Wilfart-Monziols for sharing their expert knowledge.

\section{Supplementary Material}

A supplementary file is provided that contains additional method descriptions and results. The land class dataset is available on Zenodo (https://doi.org/10.5281/zenodo.3706470), and for the model code, a GitHub repository was created (https://github.com/christianbuschbeck/RegionalFood-MO).

\section{References}

Andersson, K., \& Ohlsson, T. (1999). Life cycle assessment of bread produced on different scales. The International Journal of Life Cycle Assessment, 4(1), 25-40. https://doi.org/10.1007/BF02979392

Azadi, H., Schoonbeek, S., Mahmoudi, H., Derudder, B., De Maeyer, P., \& Witlox, F. (2011). Organic agriculture and sustainable food production system: Main potentials. Agriculture, Ecosystems \& Environment, 144(1), 92-94. https://doi.org/10.1016/j.agee.2011.08.001

Bäck, T., \& Schwefel, H.-P. (1993). An overview of evolutionary algorithms for parameter optimization. Evolutionary Computation, 1(1), 1-23. https://doi.org/10.1162/evco.1993.1.1.1

Badgley, C., Moghtader, J., Quintero, E., Zakem, E., Chappell, M. J., Avilés-Vázquez, K., Samulon, A., \& Perfecto, I. (2007). Organic agriculture and the global food supply. Renewable Agriculture and Food Systems, 22(2), 86-108. https://doi.org/10.1017/S1742170507001640

Blasco, X., Herrero, J. M., Sanchis, J., \& Martínez, M. (2008). A new graphical visualization of n-dimensional Pareto front for decision-making in multiobjective optimization. Information Sciences, 178(20), 3908-3924. https://doi.org/10.1016/j.ins.2008.06.010

Blay-Palmer, A., Santini, G., Dubbeling, M., Renting, H., Taguchi, M., \& Giordano, T. (2018). Validating the city region food system approach: Enacting inclusive, transformational city region food systems. Sustainability, $10(5), 1680$. https://doi.org/10.3390/su10051680 
Journal of Agriculture, Food Systems, and Community Development

ISSN: 2152-0801 online

https://www.foodsystemsjournal.org

BMU. (n.d.). Climate Action Plan 2050-Germany's long-term emission development strategy. Retrieved from Federal Ministry for the Environment, Nature Conservation and Nuclear Safety website:

https://www.bmu.de/en/topics/climate-energy/climate/national-climate-policy/greenhouse-gas-neutral-germany$\underline{2050 /}$

Born, B., \& Purcell, M. (2006). Avoiding the local trap: Scale and food systems in planning research. Journal of Planning Education and Research, 26(2), 195-207. https://doi.org/10.1177/0739456X06291389

Brunori, G., Galli, F., Barjolle, D., van Broekhuizen, R., Colombo, L., Giampietro, M., .. . Touzard, J.-M. (2016). Are local food chains more sustainable than global food chains? Considerations for assessment. Sustainability, 8(5), 449. https://doi.org/10.3390/su8050449

Bundesamt für Kartographie und Geodäsie [BKG]. (n.d.). Produkte und Services. Dienstleistungszentrum BKG. Retrieved June 30, 2020, from http://www.geodatenzentrum.de/geodaten/gdz rahmen.gdz div?gdz spr=deu\&gdz akt zeile $=5 \& g d z$ anz zeile $=1 \& g \mathrm{~d} z$ unt zeile $=13 \& \mathrm{gdz}$ user $\mathrm{id}=0$

BKG. (2018). CORINE land cover 10 ha. Retrieved from https://gdz.bkg.bund.de/index.php/default/digitale-geodaten.html? $\quad$ store=default

Clancy, K., Bonanno, A., Canning, P., Cleary, R., Conrad, Z., Fleisher, D., ... Tichenor, N. (2017). Using a market basket to explore regional food systems. Journal of Agriculture, Food Systems, and Community Development, 7(4), 163-178. https://doi.org/10.5304/jafscd.2017.074.018

Coello Coello, C., A., Aguirre, A., H., \& Zitzler, E. (2005). Evolutionary multi-criterion optimization. Proceedings of the Third International Conference on Evolutionary Multi-Criterion Optimization, Guanajuato, Mexico (LNCS-3410). https://doi.org/10.1007/b106458

Connor, D. J. (2008). Organic agriculture cannot feed the world. Field Crops Research, 106(2), 187-190. https://doi.org/10.1016/j.fcr.2007.11.010

Deb, K. (2014). Multi-objective optimization. In E. K. Burke \& G. Kendall (Eds.), Search methodologies: Introductory tutorials in optimization and decision support techniques (pp. 403-449). Boston, MA: Springer US. https://doi.org/10.1007/978-1-4614-6940-7 15

Deb, K., Pratap, A., Agarwal, S., \& Meyarivan, T. (2002). A fast and elitist multiobjective genetic algorithm: NSGA-II. IEEE Transactions on Evolutionary Computation, 6(2), 182-197. https://doi.org/10.1109/4235.996017

Edwards-Jones, G. (2010). Does eating local food reduce the environmental impact of food production and enhance consumer health? Proceedings of the Nutrition Society, 69(4), 582-591. https://doi.org/10.1017/S0029665110002004

Edwards-Jones, G., Milà i Canals, L., Hounsome, N., Truninger, M., Koerber, G., Hounsome, B., . . Jones, D. L. (2008). Testing the assertion that 'local food is best': The challenges of an evidence-based approach. Trends in Food Science \& Technology, 19(5), 265-274. https://doi.org/10.1016/j.tifs.2008.01.008

Ehrgott, M. (2012). Vilfredo Pareto and multi-objective optimization. Documenta Mathematica. (Extra Volume ISMP), 447453. Retrieved from https://www.elibm.org/issue? $q=$ se:2204+in:316843

Erb, K.-H., Haberl, H., Krausmann, F., Lauk, C., Plutzar, C., Steinberger, J., . . Pollak, G. (2009). Eating the planet: Feeding and fuelling the world sustainably, fairly and bumanely-a scoping study (Working Paper No. 116). Postdam and Vienna: Institute of Social Ecology.

Feldmann, C., \& Hamm, U. (2015). Consumers' perceptions and preferences for local food: A review. Food Quality and Preference, 40(A), 152-164. https://doi.org/10.1016/j.foodqual.2014.09.014

Foley, J. A., Ramankutty, N., Brauman, K. A., Cassidy, E. S., Gerber, J. S., Johnston, M., ... Zaks, D. P. M. (2011). Solutions for a cultivated planet. Nature, 478(7369), 337-342. https://doi.org/10.1038/nature10452

Galán-Martín, Á., Vaskan, P., Antón, A., Esteller, L. J., \& Guillén-Gosálbez, G. (2017). Multi-objective optimization of rainfed and irrigated agricultural areas considering production and environmental criteria: A case study of wheat production in Spain. Journal of Cleaner Production, 140(2), 816-830. https://doi.org/10.1016/j.jclepro.2016.06.099

Goedkoop, M. J., Heijungs, R., Huijbregts, M. A., De Schryver, A., Struijs, J., van Zelm, R. (2009). ReCiPe 2008: A life cycle impact assessment method which comprises harmonised category indicators at the midpoint and the endpoint level (First Ed.), Report I: Characterisation. Ruimte en Milieu: Ministerie van Volkshuisvesting, Ruimtelijke Ordening en Milieubeheer. 
Journal of Agriculture, Food Systems, and Community Development ISSN: 2152-0801 online

https://www.foodsystemsjournal.org

Griffin, T., Peters, C., Fleisher, D., Conard, M., Conrad, Z., Tichenor, N., McCarthy, A., Piltch, E., Resop, J., \& Saberi, H. (2018). Baselines, trajectories, and scenarios: Exploring agricultural production in the northeast U.S. Journal of Agriculture, Food Systems, and Community Development, 8(2), 23-37. https://doi.org/10.5304/jafscd.2018.082.015

Hedden, W. P. (1929). How great cities are fed. Boston, MA: D.C. Health and Company.

Holzkämper, A., Klein, T., Seppelt, R., \& Fuhrer, J. (2015). Assessing the propagation of uncertainties in multi-objective optimization for agro-ecosystem adaptation to climate change. Environmental Modelling \& Software, 66, 27-35. https://doi.org/10.1016/i.envsoft.2014.12.012

Jones, A. (2002). An environmental assessment of food supply chains: A case study on dessert apples. Environmental Management, 30(4), 560-576. https://doi.org/10.1007/s00267-002-2383-6

Kaule, G., Stahr, K., Zeddies, J., Angenendt, E., Bakara, H., Billen, N., . . Schwarz-von-Raumer, H. G. (2011). Nachwachsende Energieträger und Biodiversität: Naturschutzbezogene und ökonomische Entwicklung und Bewertung von Anbauszenarien (NawEnNat). LUBW.

Konak, A., Coit, D. W., \& Smith, A. E. (2006). Multi-objective optimization using genetic algorithms: A tutorial. Reliability Engineering \& System Safety, 91(9), 992-1007. https://doi.org/10.1016/j.ress.2005.11.018

Köppen, M., \& Yoshida, K. (2007). Substitute distance assignments in NSGA-II for handling many-objective optimization problems. In S. Obayashi, K. Deb, C., Poloni, T. Hiroyasu, \& T. Murata (Eds.), Evolutionary multicriterion optimization (vol. 4403). Berlin: Springer.

KTBL. (2009). Faustzablen für die Landwirtschaft. Yara.

Lautenbach, S., Volk, M., Strauch, M., Whittaker, G., \& Seppelt, R. (2013). Optimization-based trade-off analysis of biodiesel crop production for managing an agricultural catchment. Environmental Modelling \& Software, 48, 98-112. https://doi.org/10.1016/j.envsoft.2013.06.006

Meier, T., \& Christen, O. (2013). Environmental impacts of dietary recommendations and dietary styles: Germany as an example. Environmental Science \& Technology, 47(2), 877-888. https://doi.org/10.1021/es302152v

Messac, A. (1996). Physical programming-Effective optimization for computational design. ALAA Journal, 34(1), 149158. https://doi.org/10.2514/3.13035

Milà i Canals, L., Cowell, S. J., Sim, S., \& Basson, L. (2007). Comparing domestic versus imported apples: A focus on energy use. Environmental Science and Pollution Research_International, 14(5), 338-344. https://doi.org/10.1065/espr2007.04.412

Ministerium für Ernährung \& Landwirtschaft. (2016). Statistisches Jahrbuch über Ernährung, Landwirtschaft und Forsten der Bundesrepublik Deutschland. Landwirtschaftsverlag Münster. Retrieved from https://www.bmelstatistik.de/fileadmin/SITE MASTER/content/Jahrbuch/Agrarstatistisches-Jahrbuch-2016.pdf

Ministerium für Ländlichen Raum [MLR] \& Verbraucherschutz Baden-Württemberg. (2019). Bio-Musterregionen in Baden-Württemberg. Retrieved from https://mlr.baden-wuerttemberg.de/de/unserethemen/landwirtschaft/oekologischer-landbau/bio-musterregionen/

MLR. (2017). Natürlich aus der region. Retrieved June 30, 2020, from https://mlr.baden-wuerttemberg.de/de/unsere-themen/landwirtschaft/

Mondelaers, K., Aertsens, J., \& van Huylenbroek, G. (2009). A meta-analysis of the differences in environmental impacts between organic and conventional farming. British Food Journal, 111(10), 1098-1119. https://doi.org/10.1108/00070700910992925

MUKE BW. (n.d.). Ministerium für Umwelt Klima und Energiewirtschaft Baden-Württemberg. Retrieved from https://um.baden-wuerttemberg.de/de/umwelt-natur/schutz-natuerlicher-lebensgrundlagen/stickstoff/

Muller, A., Schader, C., El-Hage Scialabba, N., Brüggemann, J., Isensee, A., Erb, K.-H., . . Niggli, U. (2017). Strategies for feeding the world more sustainably with organic agriculture. Nature Communications, 8(1), 1290. https://doi.org/10.1038/s41467-017-01410-w

Organization for Economic Co-operation and Development [OECD]. (2019). Employment by activity (indicator). Retrieved June 30, 2020, from https://data.oecd.org/emp/employment-by-activity.htm

Peters, C. J., Bills, N. L., Lembo, A. J., Wilkins, J. L., \& Fick, G. W. (2009). Mapping potential foodsheds in New York State: A spatial model for evaluating the capacity to localize food production. Renewable Agriculture and Food Systems, 24(1), 72-84. https://doi.org/10.1017/S1742170508002457 
Journal of Agriculture, Food Systems, and Community Development

ISSN: 2152-0801 online

https://www.foodsystemsjournal.org

Peters, C., Wilkins, J., Rosas, S., Pepe, B., Picardy, J., \& Fick, G. (2016). Engaging stakeholders to refine models of statelevel food self-reliance. Journal of Agriculture, Food Systems, and Community Development, 6(4), 55-69. https://doi.org/10.5304/jafscd.2016.064.003

Pfenninger, S., Hawkes, A., \& Keirstead, J. (2014). Energy systems modeling for twenty-first century energy challenges. Renewable and Sustainable Energy Reviews, 33, 74-86. https://doi.org/10.1016/i.rser.2014.02.003

Pradhan, P., Lüdeke, M. K. B., Reusser, D. E., \& Kropp, J. P. (2014). Food self-sufficiency across scales: How local can we go? Environmental Science \& Technology, 48(16), 9463-9470. https://doi.org/10.1021/es5005939

proBiene-Freies Institut für ökologische Bienenhaltung (2019). Bienen-Volksbegehren: Keine mobilisierung mehr. Retrieved from https://volksbegehren-artenschutz.de/presse

Reganold, J. P., \& Wachter, J. M. (2016). Organic agriculture in the twenty-first century. Nature Plants, 2, 15221. https://doi.org/10.1038/nplants.2015.221

Rippel, R. (2014). Landwirtschaftlicher Pflanzenbau: Grundlagen des Acker- und Pflanzenbaus, der guten fachlichen Praxis, der Verfahrenstechnik sowie der Agrarmeteorologie und des Klimawandels - Produktions- und Verfahrenstechnik der Kulturpflanzen - Dauergrünland - Sonderkulturen - nachwachsende Rohstoffe - ökologischer Landbau - Naturschutz und Landschaftspflege - Feldversuchswesen - Waldbewirtschaftung. BLV-Buchverl. Landwirtschaftsverl.

Saunders, C. M., Barber, A., \& Taylor G. J. (2006). Food miles-comparative energy/emissions performance of New Zealand's agriculture industry (AERU Research Report No. 258). Retrieved from Lincoln University website: https://hdl.handle.net/10182/125

Schlich, E., \& Fleissner, U. (2005). The ecology of scale: Assessment of regional energy turnover and comparison with global food. The International Journal of Life Cycle Assessment, 10(3), 219-223. https://doi.org/10.1065/lca2004.09.180.9

Schmidt-Traub, G., Obersteiner, M., \& Mosnier, A. (2019). Fix the broken food system in three steps. Nature, 569, 181183. https://doi.org/10.1038/d41586-019-01420-2

Seufert, V., \& Ramankutty, N. (2017). Many shades of gray-The context-dependent performance of organic agriculture. Science Advances, 3(3). https://doi.org/10.1126/sciadv.1602638

Seufert, V., Ramankutty, N., \& Foley, J. A. (2012). Comparing the yields of organic and conventional agriculture. Nature, 485(7397), 229-232. https://doi.org/10.1038/nature11069

Smith, L. G., Kirk, G. J. D., Jones, P. J., \& Williams, A. G. (2019). The greenhouse gas impacts of converting food production in England and Wales to organic methods. Nature Communications, 10(1), 4641. https://doi.org/10.1038/s41467-019-12622-7

Smith, P., Bustamante, M., Ahammad, H., Clark, H., Dong, H., Elsiddig, E. A., ... Tubiello, F. (2014). Agriculture, forestry and other land use (AFOLU). In Climate Change 2014: Mitigation of Climate Change, IPCC Working Group III Contribution to AR5. Cambridge, UK: Cambridge University Press.

Stadig, M. (2001). Life cycle assessment of apple production - case studies for Sweden, New Zealand and France (SIK-Rapport No. 6832001).

Statista. (2013). Marktanteil von biolebensmitteln in Deutschland nach produktgruppen in den Jahren 2009 und 2013. Retrieved from https://de.statista.com/statistik/daten/studie/360583/umfrage/marktanteil-von-biolebensmittelnin-deutschland-nach-produktgruppen/

Statistische Ämter des Bundes \& der Länder. (2018). Zensus 2011. Retrieved from https://www.zensus2011.de/DE/Home/Aktuelles/DemografischeGrunddaten.html

Stoate, C., Boatman, N. D., Borralho, R. J., Rio Carvalho, C., de Snoo, G. R., \& Eden, P. (2001). Ecological impacts of arable intensification in Europe. Journal of Environmental Management, 63(4), 337-365. https://doi.org/10.1006/jema.2001.0473

Strolling of the Heifers. (2019). Locavore index 2019: Agriculture census data shakes up the Locavore Index; Vermont still on top; California jumps to second place. Retrieved from: https://www.strollingoftheheifers.com/locavore/

Theurl, M. C. (2016). Local food systems and their climate impacts: A life cycle perspective. In J. Niewöhner, A. Bruns, P. Hostert, T. Krueger, J. Ø. Nielsen, H. Haberl,. . . D. Müller (Eds.), Land Use Competition: Human-Environment Interactions (pp. 295-309). Cham: Springer. https://doi.org/10.1007/978-3-319-33628-2 18 
Tilman, D., \& Clark, M. (2014). Global diets link environmental sustainability and human health. Nature, 515(7528), 518522. https://doi.org/10.1038/nature13959

Tuomisto, H. L., Hodge, I. D., Riordan, P., \& Macdonald, D. W. (2012). Does organic farming reduce environmental impacts? A meta-analysis of European research. Journal of Environmental Management, 112, 309-320. https://doi.org/10.1016/j.jenvman.2012.08.018

Tusar, T., \& Filipic, B. (2015). Visualization of Pareto front approximations in evolutionary multiobjective optimization: A critical review and the Prosection Method. IEEE Transactions on Evolutionary Computation, 19(2), 225-245. https://doi.org/10.1109/TEVC.2014.2313407

Umwelt Bundesamt [UBA]. (2018). Ammoniak-Emissionen. Retrieved from https://www.umweltbundesamt.de/daten/luft/luftschadstoff-emissionen-in-deutschland/ammoniakemissionen\#textpart-1

United Nations Environment Programme [UNEP]. (2013). Emerging issues in our global environment (UNEP yearbook: Vol. 2013). Nairobi, Kenya: United Nations Environment Programme. Retrieved from UNEP website: https://www.unenvironment.org/resources/year-books

United Nations General Assembly. (2015, September 1). Draft outcome document of the United Nations summit for the adoption of the post-2015 development agenda (Resolution 69/315). Retrieved from: https://www.un.org/en/ga/69/resolutions.shtml

VELA. (2014). Landwirtschaftlicher Pflanzenbau: Grundlagen des Acker- und Pflanzenbaus, der guten fachlichen Praxis, der Verfahrenstechnik sowie der Agrarmeteorologie und des Klima-wandels - Produktions- und Verfahrenstechnik der Kulturpflanzen - Dauergrünland - Sonderkulturen - nachwachsende Rohstoffe - ökologischer Landbau Naturschutz und Landschaftspflege - Feldversuchswesen - Waldbewirtschaftung (13th ed.): BLV München.

Zasada, I., Schmutz, U., Wascher, D., Kneafsey, M., Corsi, S., Mazzocchi, C., . . Piorr, A. (2019). Food beyond the city - Analysing foodsheds and self-sufficiency for different food system scenarios in European metropolitan regions. City, Culture and Society, 16, 25-35. https://doi.org/10.1016/j.ccs.2017.06.002

Zepeda, L., \& Deal, D. (2009). Organic and local food consumer behaviour: Alphabet Theory. International Journal of Consumer Studies, 33(6), 697-705. https://doi.org/10.1111/j.1470-6431.2009.00814.x 